\title{
Error Correction and the Improvement of Language Form ${ }^{1}$
}

Devon Woods

This article discusses some of the complexities inherent in teachers' practices of correcting second language students' spoken and written errors. It then discusses some alternatives to error correction, as a means of improving students' language form.

In a paper on learners' errors written by a teacher enrolled in the Certificate course in Teaching ESL at Carleton University, Munro-deLeeuw described the means she used to improve the language form of a group of her students whose English was filled with recurring "fossilized" errors.

In the classroom I was strict. The chatter was held to a minimum and even in spontaneous conversation I corrected their errors. I encouraged them to repeat sentences in the hope that they would begin to develop their own internal "monitor" system. As I look back through the diary I kept, I was encouraged by the number of times my students would stop and say, "Is that how you say that? No one ever told us that before." This was further proof I thought, that with more time and practice the old patterns would change. After about three months, there was a slight change when the students were in the classroom, however, in conversations at coffee breaks or on the street, I began to realize that nothing was changing ...

(Munro-deLeeuw, 1985)

Her conclusions from this experience have also been echoed by many experienced teachers, with regard to both oral and written production. In the professional literature, authors have arrived at similar conclusions. For example, Lightbown (1985:178) notes that "isolated explicit error correction is usually ineffective in changing language behaviour".

However, the issue of students' formal errors in the second language and how to deal with them still remains a concern for both experienced teachers and teachers-in-training. In particular, with the current emphasis on communication in language teaching, theorists (for example, Clifford and Higgs, 1982) and teachers have noted the lack of a theoretical perspective and practical methods for resolving students' formal errors. Advocates of communicative teaching argue that explicitly correcting students' errors detracts from language learning, on the grounds that communication rather than accuracy is the goal of language teaching, that acquisition of language form occurs through a focus on meaning rather than through a focus on 
form, and that correction produces negative psychological consequences in the learner.

In spite of these claims, however, many teachers (and students as well) express a view that errors should not be ignored, and that language form can and should be improved by focussing on form. This issue of error correction and the desirability or necessity of focussing on form in second language teaching was a central issue in the Symposium on the Development of Bilingual Proficiency in Toronto in 1987. The issue was raised in the initial presentation, by Allen and Swain, of the research of Harley, Allen, Cummins and Swain (1987), and debated in responses by Paulston and Lightbown. Paulston suggested that in embracing a non-interventionist communicative approach, we may have thrown the baby out with the bathwater, and "now it's time to get the baby back". Lightbown, in her response, agreed with Paulston, but stated that there is no evidence to suggest that "to get the baby back-we have to take the bathwater" (Lightbown, 1987).

In this article, I would like to discuss some of the factors related to the lack of success of error correction: the complexities involved in determining what constitutes an error in a specific situation, and in consistently representing to the learner and having the learner correctly interpret what the error is. Then I would like to discuss some alternatives to error correction as a means of improving language form within a communicative orientation to language teaching.

\section{The Complexity of Error Correction}

It is becoming clear as researchers look more closely at teacher-student interactions in the classroom that correcting errors, both in spoken and written production, is a very complex task. The complexity lies in two important areas:

(i) deciding that an error has occurred and interpreting what the error is, and

(ii) being fair, consistent and correct in the treatment of the error.

\section{How do we decide what is an error and what is not?}

Any consideration of how to correct errors presupposes another important question: what is an error? Or rather, what is the standard that we are using as our basis for comparison to what the learners produce? Presumably, if we are going to make consistent corrections, we must have some idea of a correct standard in order to help us judge what is an error and what is not.

Some teachers use native-speaker English as the standard for comparison. In other words, students are corrected when their production is considered to deviate from what a native speaker would produce. Other 
teachers feel that second language students should not be expected to reach native speaker accuracy, and have in mind some abstract norm of a very good non-native speaker of English. Still other teachers feel that native speakers also make errors, both in writing and speaking, and have in mind (although perhaps subconsciously) a kind of idealized norm which is beyond what native speakers produce. However, this idealized norm could be based on one of a number of conceptual distinctions: based on a notion of performance as opposed to competence, based on a notion of standardized norm versus particular dialects or idiolects, or based on prescriptive textbook grammar versus descriptions of contemporary use.

This issue of a standard of "correct English" is further complicated by the differences between written and spoken language and by differences in degrees of formality. Informal spoken language with its incomplete and interrupted utterances is quite different from formal written language. Between these extremes is a range of variation, including, for example, formal spoken language in an oral presentation and informal written letters to a friend. Genre-based and situational constraints also play a role. Certain usages may be used correctly and appropriately in particular discourse communities or situations but not in others (for example, a connector such as indeed, or the use of the present perfect in scientific texts). Such differences are not always taken into account by teachers who demand spoken answers characteristic of formal written language (for example, in complete sentences), or correcting an informally written student journal. In a classroom situation, which can at best only simulate or explain some of these degrees of formality and situational constraints, it is difficult to have an unambiguous standard for comparison.

All this means that the criteria for deciding what to consider an error are not at all straightforward. How do teachers decide then? Probably most teachers (including me) use as a model a combination of the way we think we speak (which is probably not identical to the way we actually speak, judging by our surprise upon hearing a tape of our speech), and the way we think we should speak, based on the prescriptions of our own composition teachers and grammar books. The fact that what we tell the students is different from what we actually do ourselves means in effect that we are telling the students to do what we say but not what we do, (or rather, we are telling them to say what we say we say, but not what we actually say).

Besides this question of a correct standard, there is also the question of which aspects of language we consider in checking for errors. In written language, aspects readily corrected are grammar, spelling and punctuation, while in oral language pronunciation and grammar are usually treated. Regarding pronunciation, we find that articulation of sounds is often corrected, but intonation patterns (to some extent the spoken equivalent of 
punctuation) are rarely corrected. It is not clear why this is the case; perhaps because we ourselves learned discrete rules for punctuation in school, but not for intonation. It is nonetheless clear that different aspects of language are arbitrarily and inequitably emphasized in our error correction.

It is also not necessarily the case that correction takes place with regard to the formal aspects of language. There are other areas of language which are sometimes, but inconsistently, considered for correction. For example, we may occasionally correct function (words which indicate what you are trying to do with what you say). We may correct the impression created (words which indicate whether you are being polite or rude, friendly or distant, agreeable or disagreeable). We may correct cohesion (use of referring words, repetition or variation, ellipsis, the formal relationships among sentences), and coherence (use of words to relate to the context of the situation and of what was previously said). At this point, our discussion is moving away from matters of form per se, and toward the relationship of form to meaning. This complicates the situation further. Should we correct things which are grammatically correct but factually or communicatively incorrect? Should we or can we correct things which are grammatical but do not mean what the speaker intended?

Why do we choose to correct certain errors with regard to certain aspects of language but leave others uncorrected? There are many possible reasons other than the structure of the target language. It seems likely that many teachers determine errors idiosyncratically: errors which come to their attention and which strike them as being serious. In other words, they correct ones which are easy to label, easy to correct, and easy to give rules for, ones which they are good at correcting and have a routine for.

One might argue that this theoretical argument about identifying errors is not relevant in practice. That when faced with non-native speakers, it is easy to recognize what their blatant errors are and to correct them. In fact, things are even more complicated in practice, in trying to determine (with regard to both spoken or written production), what error has occurred, whether or not it should be corrected or allowed to pass, and if it is to be corrected, how this correction should be done.

Let me provide an example of this complexity with a paragraph from a written report done by a student in an advanced ESL writing class:

Thai family style is much more serious and official compared to the Canadian style. In this case, I would like to mention respecting manner. For example, Thai children usually speak to their parents respectfully. They never try to tease their parents with funny words or impolite words. However, Thai parents firstly think about their relationship bound to their children most of the time whenever conflicts come. Consequently, divorce rate in Thailand is less than in Canada. 
This report was well done overall-the student made a clear and wellorganized demonstration of important cultural differences between certain areas of Thai life and Canadian life. Nevertheless, this paragraph and many others contained many potentially correctable items. For example, with the word respecting does the student mean with respect to or giving respect? With manner does the student mean the way something is done or manners? Two interpretations of the combination of these two words, $I$ would like to mention something with respect to manners and I would like to mention something about the manner of giving respect, mean just about the same thing. However, in dealing with this sentence in terms of form, and in terms of errors, these two interpretations are quite different. There are also more subtle questions, such as is the expression family style appropriate here, or is there a more appropriate way to indicate what the student means? How about the term official? How about an article the preceding Thai family style; is the student trying to indicate that this style is a unified single style (which would require the), or is she referring to a more nebulous, not clearly identifiable set of styles (which would be better rendered as she has done it). There is enough in this single paragraph to keep a teacher pondering for an entire evening.

Of course, the matter is relatively less complex when the work to be corrected is written and when the teacher has time to think things over. When the student is speaking or interacting, the corrector's job of noticing, deciding what kind of error has occurred, deciding when and how to intervene, determining an appropriate correct form, deciding how best to present the appropriate correction to the student, and carrying all this out, becomes overwhelming.

\section{Consistency in Treatment of Errors}

With this complexity in interpreting errors, is there any hope or likelihood of being consistent when we treat students' errors? Discussions on correction (or teachers' evaluation of students' responses), both in the fields of ESL teaching and of primary education, seem to say not.

Mehan (1974), discussing teaching in primary education, shows that consistency in responding to students production may not be possible to achieve in practice. He gives a number of examples of a teacher providing inconsistent evaluation of students' answers, where standards seem to change frequently and randomly during a lesson, especially in cases where there is a conflict between the grammatical accuracy and factual accuracy of a student's answer. This inconsistency was noted even when, after the lesson in question, the teacher reported having reacted in a consistent way according to explicit criteria. Mehan describes Schutz' (1970) concept of perceptual relevance to explain these observations. According to Schutz, 
a teacher's attention cannot be on all the features of a classroom scene simultaneously. When one problem or issue is in the foreground of perception, others must necessarily slip to the background. As the scene changes, and "systems of relevance" are modified from one moment to the next, a problem previously of little concern may be brought to the centre of focus. When a child answers a question, the teacher's focus may be on the factual correctness of the answer at the expense of its formal correctness or vice versa, or indeed on neither of these if pressures from other areas of the classroom are too great. "But, in the very next moment, the teacher may be freed of these pressures and her attention can be focussed more intently on the question she is asking. When her attention is not divided, she is able to focus on children's needs and mistakes. Descriptions (and criticisms) of the teacher's evaluations of children must take these situationally based, moment-to-moment shifts in the teacher's attention into account" (Mehan, 1974:94).

This phenomenon occurs as naturally in second language classrooms as it does in primary classrooms. Allwright (1977:106-7) illustrates, in a study made of teachers' treatment of learner error, the unsystematic approach to the choice of error to be treated, to the indication of the location of the error, and to the type of treatment chosen. He then takes the learner's perspective, trying to hypothesize what their interpretations of the teacher's responses to their production might be. To do this, he constructs a sample interaction between teacher and learners (one slightly simplified but typical of those he found in his analysis):

Teacher: When's your birthday, Alvaro?

Alvaro: Twelfth November.

Teacher: Okay. Now Santos, when's your birthday?

Santos: Fourteenth of September.

Teacher: No. Listen: the fourteenth. Again . . .

He then gives a plausible reason why such differential treatment of errors might occur: Alvaro is known to the teacher as someone who pays no attention to correction and does not seem to learn from it, therefore time spent on correcting him would be wasted. Santos on the other hand, is considered to be a keen student and would respond well to correction. However, as Allwright notes, there are several pertinent questions about the learners' perceptions. For example, does Santos know that the teacher thinks Alvaro is careless while he (Santos) is serious and will react well to correction? Does he know that the teacher's treatment of Alvaro is not to be considered as reliable evidence of what is or is not to be considered acceptable? Does he know that the teacher's use of the word okay is not to indicate approval, and the word no is not complete rejection but rather partial acceptance? 
If, on the other hand, Santos assumes that the correction occurs the way it does because of the nature of the target language (which is probably what, in theory, one would assume), then there are several grammatical intepretations possible. For example, the absence of the is wrong for September (or fourteenth) but obligatory or optional for November (or twelfth), Or, the presence of of necessitates the presence of the. Or, the absence of of necessitates the absence or optionalizes the presence of the. And so on.

A point that Allwright makes is that it is in fact impossible to be consistent both in terms of the target language and in terms of dealing with the needs of the individual students. Since some students may be crushed by being singled out for correction, and some may benefit in ways that others might not, being fair to the students effectively rules out being fair to the language (even if there were a single model of the target language for comparison).

With so much ambiguity in the treatment of errors, it is not surprising that teachers and researchers have found that error correction does not lead to error eradication. Probably the best summary of this phenomenon is Lightbown's (1985). In noting that language behaviour is generally not changed by isolated explicit error correction, she argues, first, that because "errors are not isolated phenomena but part of a system", there must be a restructuring of the system over time for there to be a change in language behaviour, and, second, that because learners do not get reliable correction from teachers, and they do not necessarily interpret correction in appropriate ways. To illustrate, Lightbown describes a teacher, who, in order to indirectly correct a student's error, often asks another student the same question, thereby eliciting the correct answer. In the exchange below, however, the teacher is using a similar technique, not to correct the student, but to elicit another form of the auxiliary. However, the student incorrectly interprets the teacher's behaviour as a correction.

Teacher: Do you like apples?

Student A: No, I don't.

Teacher: (addressing Student B but pointing to Student A) Does he like apples?

Student B: No, he doesn't.

Student A: (whispering) No, I doesn't.

(Lightbown, 1985:178)

If error correction does so little good, why do we persist in doing it? One reason is that our culture still carries vestiges of popular behaviourism (i.e. get into good work habits, don't practice bad habits or you won't be able to get rid of them, get in the habit of brushing your teeth after each meal, and so on). Another reason is perhaps because every once in a 
while, in a memorable way, correcting an error does seem to work. Most teachers know of a couple of instances in their own personal experiences as learners or teachers when, for some reason, a correction made a difference. It seems certain, however, in those cases that work, that there are certain conditions that must be satisfied, beyond the straightforward correction, for a change to take place. Perhaps the correction has to be somehow memorable or emotion-laden, and/or the learner must have sufficient motivation (or perhaps a desire to sound just like a native speaker), and/or the learner's system must be ready to integrate this new aspect of the language. Perhaps learners follow the principles of a Kuhnian paradigm, ignoring all evidence contradicting their present state until a critical point is reached at which the system becomes ready to readjust, and, as a result, the learners are particularly open to a correction.

\section{Alternatives to Error Correction for Improving Language Form}

If the ultimate goal of error correction is better form (i.e. production which is more grammatical, and which sounds or looks more native-like), then perhaps the question what is the best way to correct errors? is better recast as what is the best way to improve form? This question leads to possibilities other than error correction, ones which treat form in both explicit and implicit ways. Some examples are:

- by focussing on real communicative consequences of inaccuracy

- by teaching strategies for attending to form when listening or reading

- by putting the responsibility on the learners for monitoring their own form. There is currently some interesting work developing in some of these areas: Allen and Waugh (1986), Ricard (1986), Woods (1984), among others.

\section{Focus on Form in Communicative Situations}

One possible way to deal with form is not to teach or correct elements of form directly, but to teach strategies for learning form from the communicative situations learners find themselves in. (This is not to be considered an alternative to focussing on communication, but rather an alternative to correcting errors.) The first necessity, then, is to develop activities and assignments which put the learner into situations in which the target language is being used-in particular ones similar to those the learner wishes to be able to function in. Sawkins (1987:69-70), for example, outlines a number of such "activities for global practice". Once in these situations, there are ways in which learners can be advised or taught to spend some of the time attending to form. (This is not to say that they will not also need to be taught techniques to avoid focussing on form and 
to concentrate on the message. This is a separate but essential skill.) For example, if learners find themselves in situations where native speakers are talking about things that happened to them (anecdotes are a frequently occurring type of oral discourse structure), there are a number of possible strategies for focussing on form, such as:

1. In the early stages of learning the new language, when the discussion is still mostly meaningless and the learners are primarily observers (or they are lost or tired of trying to understand the meaning), they can listen to and watch the paralinguistic aspects of the language: the rhythm, the pitch, the intonation curve, the voice quality, the hand and face movements, and also the individual sounds and sequences of sounds. This would, at the least, reduce their frustration and boredom by giving them something to focus on. At the most it could have some positive effect on their ability to sound like a native speaker.

2. At a later stage, when words begin to make sense, they can listen for recurring patterns of words-groups of words that sound like they go together in a particular order.

3. With a small cassette recorder (if this is socially acceptable), they can capture 4-5 minutes of a discussion every couple of days, then listen to it, trying to recognize the words, then try to write them down, repeat the sounds in their mind and then on tape, and become familiar with the words and sequences for subsequent discussions.

4. They can become aware of the naturally occurring units in the discussion-for example when one anecdote in a conversation ends and another begins-and pay attention to words or chunks which occur typically within those units. Being aware of the larger discourse unit (anecdotes) and the social situation (out with friends) can assist the learner in becoming familiar with and recalling the words, structures, collocations, expressions and larger chunks of language which are typical to that context.

These are all areas which can be prepared for and discussed in class, and on which students can report back to their classmates and teachers. From such activities, students can learn early on that a focus on form in communicative situations is possible, and is, in fact, an ability that can be developed.

The teacher can also contribute to improved form by simply exposing the learner to plenty of communicative input, especially in situations and discourse structures similar to those that the learner is trying to learn, and by taking into account students' goals when providing input. For example, having an engineer or a musician come to the classroom as a guest speaker for students who identify strongly with that career choice will certainly result in their listening closely, and may eventually affect their openness to changes in form. 
There are a number of points to keep in mind here. First, there is an implication that an awareness of form improves form. Although this relationship is assumed by many authors and teachers, there is as yet no clear evidence that this is necessarily the case. Second, this kind of focus in learning assumes that students are very integratively motivated-that they want to sound like native speakers. Many students, although they want to live in Canada, and to work or study and succeed, do not want to give up their own culture. They may have no wish to speak English with entirely English-Canadian characteristics: they identify primarily with others of their culture, and, as long as it does not hinder their success, want (consciously or unconsciously) to retain that identity in their speech. In considering their situation, the question of form, per se, becomes less relevant. What is more relevant is form as it relates to communication.

\section{Form and Miscommunication}

If we are going to think about form within a communicative context, it means that we have to view form quite differently. There is a sense in which we can say that errors are to a structural approach what misunderstandings are to a communicative approach. The goal in a communicative approach is to have students be understood (not only on the level of words, but also on the level of intent and the level of impression-when I speak I want others to understand what I say, and what I mean with what I say, and I hope they come away with the impression that I want to convey). Misunderstandings (which in my definition can occur on any of these levels) are an indication that this goal is not being achieved, and can be an indication of where language form is not conveying what we want.

Misunderstandings are different from errors in that they cannot be corrected objectively by an outside person such as a teacher (although I have argued above that errors cannot either). Misunderstandings by definition involve an interaction between two (or more) people-mediated by an oral or written text-who both play a role in understanding or misunderstanding. In daily life, and even in classrooms, many misunderstandings pass unnoticed. If they are noticed, there is rarely an attempt by the participants to determine precisely what aspect of the communication caused the misunderstanding. But, with some analysis, and some sensitivity, it is possible to become aware of precisely which features of the communication are likely to cause the misunderstanding. This is discussed in a little more detail in Woods (1984:120).

This view implies that learners need to get communicative feedback, and become sensitized to specific causes of misunderstandings. A communicative classroom, with lots of interaction and groupwork naturally provides such feedback. In fact, students have to be more careful about 
form when talking to other students of different backgrounds than they do when talking to a teacher who is experienced at understanding them. Nevertheless, the teacher can play a role in leading the learners to an increased sensitivity and to a certain attention to the communicative aspects of form. First, the teacher can be an interested participant in discussions by asking questions which draw students into being more specific about what they are trying to express. This role must be handled with care; it is easy to disconcert the student as much with probing questions as with overt correction. But, when handled well, interested questioning about what the student is expressing - asking for more detail, more specific information, clarifying the people involved (ambiguous pronoun reference is one major cause of oral misunderstanding) - can allow the learner to elaborate, and reformulate, and expand his expressive ability. As well, the teacher, by reformulating, in a natural manner, what the learner is attempting to express ("Do you mean . . .?"), can model language form in context for the learner. Also, by letting the student, again in a natural manner, know the exact source of a problem in understanding (e.g. the pronunciation of a specific word, the intent behind the utterance), the teacher can provide the learner with feedback for improving form. The important word here is natural: it is important to have respect for the ecology of the conversation.

\section{Form and Thematic Language Teaching}

A current offshoot of communicative language teaching is thematic teaching, where the activities and language input that the students deal with during a period of a couple of weeks are unified and given purpose by a particular theme and an overall theme-related task. (For examples, see Currie and Cray, 1987.) Themes are content based, and can be about any subject matter relevant or interesting to the students. One interesting variation on a thematic approach is one which bases its theme on aspects of language form. For example, it is conceivable to have a theme on grammar, in which students:

(i) read articles about strategies for learning grammar (from Rubin and Thompson, 1982, for example), and evaluate the strategies for themselves.

(ii) listen to a cassette tape of the teacher's feedback on their grammar problems.

(iii) keep track of their errors on a logsheet (this is a point at which the teacher can legitimately correct errors for a couple of days, because it provides students with data for their project).

(iv)discuss in small groups the areas of grammar they feel they have problems with and the strategies they could use for improvement, 
report back to the whole class, and then choose areas and partners for group research.

(v) work in groups using several grammar textbooks to research their chosen area, eventually presenting it (orally and/or in writing) to the rest of the class.

All the elements of a thematic communicative approach are here: integrated skills, small group discussion, extended listening and reading with an authentic purpose in mind, meaningful content. In addition, the theme is explicitly related to one of their purposes for taking the course-to improve their language.

I would like to make a final note: how second language learners acquire (or do not acquire) formal aspects of language is not at all well understood. Nonetheless, when communicatively organized and carried out, a focus on form in the classroom is possible. If the students' growing sensitization to form enhances their correct use of the language, so much the better. If it doesn't, then at least the focus on form is not hindering the normal process of learning through communication.

\section{NOTES}

1. I would like to acknowledge the thought-provoking feedback of Graham Smart, Ellen Ricard, Virginia Swisher and Ian Pringle on earlier drafts of this paper.

\section{REFERENCES}

Allen, W. and S. Waugh. (1986). Dealing with accuracy in communicative language teaching. TESL Canada Journal, Special Issue 1.

Allwright, R.L. (1975). Some problems in the study of teachers' treatment of learner error, in M.K. Burt and H.C. Dulay (Eds.), New Directions in Second Language Learning, Teaching and Bilingual Education.

Currie, P. and E. Cray. (1987). Strictly Academic: Reading and Writing for Academic Purposes.

Harley, B., P. Allen, J. Cummins, and M. Swain. (1987). The Development of Bilingual Proficiency, Vol. II: Classroom Treatment. Research report presented at the Development of Bilingual Proficiency Symposium, Toronto, November 19-21, 1987.

Higgs, T.V. and R. Clifford. (1982). The push toward communication, in T.V. Higgs (Ed.) Curriculum, Competence and the Foreign Language Teacher.

Lightbown, P. (1987), Process-product research on second language learning in classrooms. Discussion paper for the Development of Bilingual Proficiency Symposium, Toronto, November 19-21, 1987.

Lightbown, P. (1985). Great expectations: second language acquisition research and classroom teaching. Applied Linguistics, Vol. 6, No. 2. 
Mehan, H. (1974). Accomplishing classroom lessons, in A. Cicourel et al, Language use and School Performance.

Munro-deLeeuw, B. (1985). Fossilized forever? Three case studies of fossilized second language learners, unpublished manuscript, Carleton University.

Ricard, E. (1986). Theory into practice: Getting students to take responsibility for their own learning outside the classroom. Paper presented at TESL Ontario Conference, Nov. 1986.

Rubin, J. and I. Thompson. (1982). How to be a More Successful Language Learner.

Sawkins, M. (1987). Training for independence in learning. TESL Canada Journal, Vol. 5, No. 1 .

Schutz, A. (1970). Reflections on the Problem of Relevance. New Haven: Yale Universiy, Press.

Woods, D. (1984). A process orientation in ESL writing. Carleton Papers in Applied Language Studies, Vol. 1.

\section{THE AUTHOR}

Devon Woods is an Assistant Professor and Coordinator of English as a Second Language in the Centre for Applied Language Studies at Carleton University. 